\section{Emergency department sedation}

To the editor:

Recently I forwarded the Canadian Association of Emergency Physicians' (CAEP) procedural sedation and analgesia guidelines ${ }^{1}$ to the anesthesia department in our hospital. I felt that they would have a harder time arguing against these guidelines than our policy, and therefore that this might be a prudent first step. I was also careful to explain that we were looking for feedback (not permission).

There must have been some pent-up frustration because the letter that we received is anything but cooperative (the language notwithstanding). The premise of the letter is that we are currently providing general anesthesia in the ED and of course should not be. I disagree with the former point and agree with the latter.

There is a great deal of ignorance out there ("Why don't you just use midazolam for induction of head injuries?"), and there is always the inter-professional rivalry factor. Our Chief of Anesthesia states that he contacted the Canadian Anaesthetists' Society (CAS), who indicated that the "CAS did not contribute to the development of the CAEP guidelines and has no comment on it." The impression I got was that CAS was involved. Could you clarify this for me?

\section{Del Donald, MD}

Sudbury, Ont.

\section{Reference}

1. Innes G, Murphy M, Nijssen-Jordan C, Ducharme J, Drummond A. Procedural sedation and analgesia in the emergency department. Canadian consensus guidelines. J Emerg Med 1999;17:145-56.

\section{Admission orders}

\section{To the editor:}

I read with interest the commentaries in $C J E M^{1-3}$ regarding emergency physicians (EPs) writing admission orders.

Does anyone think that, just maybe, writing admission orders (and having the last word on whether a patient is admitted) might reduce our legal risk? Does anyone think that the EP is in an excellent position to write comprehensive orders? Does anyone think that writing admission orders and determining patient care is a valuable skill for emergency physicians to maintain? In many cases, EP admission orders facilitate timely patient care and help alleviate emergency department (ED) congestion. Beleaguered ED nurses, as well as patients, families and relatives, appreciate prompt decisions and dispositions.

In our busy ED, emergency physicians routinely write admission orders. It is not a waste of time. It allows the EP one last opportunity to review the patient, collect his or her thoughts, and initiate timely care. Maybe, except in specialized situations like intensive care cases, emergency physicians should write all admission orders, unless consultants, residents or family docs do so as a courtesy to us.

I wonder who's really at higher medico-legal risk: emergency physicians who write orders? Or those who don't?

I hope this controversy rages on for some time to come.

\section{Michael Hebb, MD}

Dartmouth General Hospital

Dartmouth, NS

\section{References}

1. Shuster M. Who should write admission orders? CJEM 1999;1(1):21.

2. Socransky S. Admission orders [letter]. CJEM 1999;1(1):19.

3. Robson R. Admission orders [letter]. CJEM 1999;1(1):19-20.

\section{Congratulations}

To the editor:

Just a brief note to let you know that I am very impressed with CAEP's new publication. As one of those "greybeards" who was around when the Canadian Association of Emergency Physicians was first formed, I have supported the evolution of written communication from our national professional organization to its membership. CJEM represents another milestone marking the maturation of Emergency Medicine in Canada. You and your editorial board are to be congratulated on the quality of this product in which we all should take pride.

\section{Jan Ahuja, MD}

Ottawa Hospital - Civic Site

Ottawa, Ont.

jan_ahuja@sympatico.ca

\section{To the editor:}

I just reviewed the April (vol 1, no 1) issue of CJEM and found it quite refreshing. The content had a nicely balanced flavor and was intellectually stimulating as well as truly funny in places. I wish you well for the future and wonder if we could secede from Texas and join Canada.

\section{Matthew J. Walsh, MD}

Assistant Professor and Chairman Department of Emergency Medicine Texas Tech University HSC El Paso, Texas 